\title{
Impact of current video game playing on robotic simulation skills among medical students
}

\author{
Tufan Öge ${ }^{1}$, Mostafa A. Borahay², Tamar Achjian², Sami Gökhan Kılıç² \\ 'Department of Obstetrics and Gynecology, Eskişehir Osmangazi University Faculty of Medicine, Eskişehir, Turkey \\ ${ }^{2}$ Department of Obstetrics and Gynecology, The University of Texas Medical Branch, Texas, USA
}

\section{Abstract}

Objective: To evaluate the impact of current and prior video game playing on initial robotic simulation skill acquisition.

Material and Methods: This cross-sectional descriptive study (Canadian Task Force Classification II-1) was conducted at a medical university training center. The study subjects were medical students who currently played video games (Group I) and those who had not played video games in the last 2 years (Group II). The robotic skills of both groups were assessed using simulation.

Results: Twenty-two students enrolled in this study; however, only 21 completed it. The median age of the participants was 23 (22-24) years and 24 (23-26) years in Groups I and II, respectively. Among the participants, 15 (71.4\%) were male and $6(28.5 \%)$ were female, and $90.4 \%$ of the students started playing video games in primary school. When the 2 groups were compared according to the completion time of each exercise, Group I finished more quickly than Group II in the Peg Board-1 exercise ( $p>0.05$ ), whereas Group II had better results in 3 exercises including Pick and Place, Ring and Rail, and Thread the Rings-1. However, none of the differences were found to be statistically significant ( $p>.05)$, and according to the overall scores based on the time to complete exercises, economy of motion, instrument collision, use of excessive instrument force, instruments out of view, and master workspace range, the scores were not statistically different between Groups I and II ( $\mathrm{p}>.05$ ).

Conclusion: According to the basic robotic simulation exercise results, there was no difference between medical students who used to play video games and those who still played video games. Studies evaluating baseline visuospatial skills with larger sample sizes are needed.

(J Turk Ger Gynecol Assoc 2015; 16: 1-4)

Keywords: Education, medical students, robotic simulation, video games

Received: 27 October, $2014 \quad$ Accepted: 07 January, 2015

\section{Introduction}

Minimally invasive surgery (MIS) is gaining popularity as technology advances. Robot-assisted surgery represents an increasing share of MIS in the field of gynecology as well as urology and other surgical specialties. Overall, MIS has some advantages, such as decreased blood loss, less postoperative pain, shorter hospital stay, better visualization, improved postoperative recovery, and better cosmetic outcomes, compared with open surgical cases. Robotic surgery has additional technical advantages, such as 3D viewing and better dexterity compared with conventional laparoscopy. The presence of robot-assisted surgery is projected to grow in the various surgical fields. Thus, teaching robot-assisted surgical skills is becoming part of the curriculum of surgical residency programs nationwide. To create well-structured residency training, determining future surgeons' hand-eye coordination skills is a necessity (1).

One of the main disadvantages of robotic surgery is that surgeons must operate without tactile sense. Therefore, simulation training is necessary to improve the outcome of initial hands-on experiences to avoid errors and malpractice. Video games have been discussed previously in the English medical literature for the development of laparoscopic skills to improve the learning curve in simulators and in surgery (2). The idea originated from studies that pointed out that video game playing was associated with improved reaction time, spatial visualization, and mental rotation $(3,4)$. Although some authors were unable to show the beneficial effects of video game playing on the ability to learn robotic suturing (5), other studies concluded that training on video games appeared to improve laparoscopic skills (6-8). Our group previously demonstrated that residents with prior laparoscopic suturing experience may learn more quickly from robotic surgery training than those with less laparoscopic surgery experience (9).

Medical schools are currently educating a generation of students who played video games from the beginning of their childhoods. They have more ability than their older counterparts to adapt to technological developments, and their experience using computers and video game consoles may afford them an advantage in their baseline eye-brain-hand coordination skills. We therefore hypothesize that these visuospatial skills acquired from playing video games can be adapted to learning robotic surgery skills. To test this hypothesis, we 
prospectively evaluated the basic robotic simulation exercise results of medical students currently playing video games and compared them with the results of medical students who previously played video games but had not played them in the last 2 years.

\section{Material and Methods}

\section{Study design}

This was a preliminary cross-sectional descriptive study comparing the effects of current or past video game playing on the ability to perform robotic simulation exercises. The study was conducted in the Department of Obstetrics \& Gynecology at a State University and was approved by the Institutional Review Board (IRB) and the ethics committee. After signing the informed consent form, all participants answered questionnaires to obtain information about their histories with video games. The survey included questions about the participants' age, gender, time period of starting to play video games, and frequency of play, including the hours of gaming per day, hours per week, and duration of game playing time per session. Moreover, the type of console used [e.g., Xbox (Microsoft Corporation, Redmond, WA, USA), PlayStation (Sony Corporation, Minato, Tokyo, Japan), personal computers, or Wii (Nintendo, Kyoto, Japan)] and type of game played (first-person shooter, third-person shooter, racing games, sports games, strategy games, or other) were delineated.

\section{Participants and outcome measures}

We used the Mimic Technologies dV-Trainer ${ }^{\mathrm{TM}}$ platform (Mimic Technologies Inc., Seattle, WA, USA) for robotic simulation, which is a validated trainer for robotic surgery (10). The participants were divided into 2 groups according to their video game playing history (Figure 1): Group I included students who had played video games in the last 2 years $(n=11)$ and Group II included students who had not played video games in the last 2 years $(n=11)$. The participants were asked to perform 4 basic exercises: "Pick and Place," "Peg Board-1," "Ring and Rail," and "Thread the Rings-1." The objectives were to place the objects in matching colored containers, to pick up and transfer rings sequentially from peg boards to a single peg on the floor, to pick up a ring and guide the ring along a curving rail, and to pass a needle and suture through a number of flexible eyelets, respectively (Figure 2). After each exercise, the participants received overall scores out of 100 according to the time to complete the exercise, economy of motion, instrument collision, use of excessive instrument force, instruments out of view, master workspace range, and drops.

\section{Statistical analysis}

All data were initially checked for any missing variables or erroneous entries. Thereafter, data were presented as median with interquartile range. The Shapiro-Wilk test was used to check data for normal distribution. The between groups statistical analysis was performed using the Mann-Whitney rank sum nonparametric test for continuous variables and the chi-square test for categorical variables. All analyses were performed using SigmaPlot software version 12.3 (Systat software, Inc., Chicago, IL, USA). A p-value of .05 was considered statistically significant.

\section{Results}

The median age of the participants was 23 (22-24) years and 24 (23-26) years in Groups I and II, respectively. The demographic and background characteristics are shown Table 1. Among the participants, 15 (71.4\%) were male and 6 (28.5\%) were female. Gender distribution between the groups was not significant $(\mathrm{p}=.06)$. Furthermore, $90.4 \%$ of the students started playing video games in primary school. Students who continued to play video games spent $13.1 \pm 7.9 \mathrm{~h}$ per week on gaming. The type of game consoles used and games played by the participants are summarized in Table 2.

When we compared the 2 groups according to the completion time of each exercise, Group I finished Peg Board-1 more quickly than Group II ( $p>.05$ ), and Group II finished 3 exercises more quickly, including Pick and Place, Ring and Rail, and Thread the Rings-1. However, none of the differences were found to be statistically significant ( $p>.05$ ) (Table 3). According to the overall scores based on the completion time, economy of

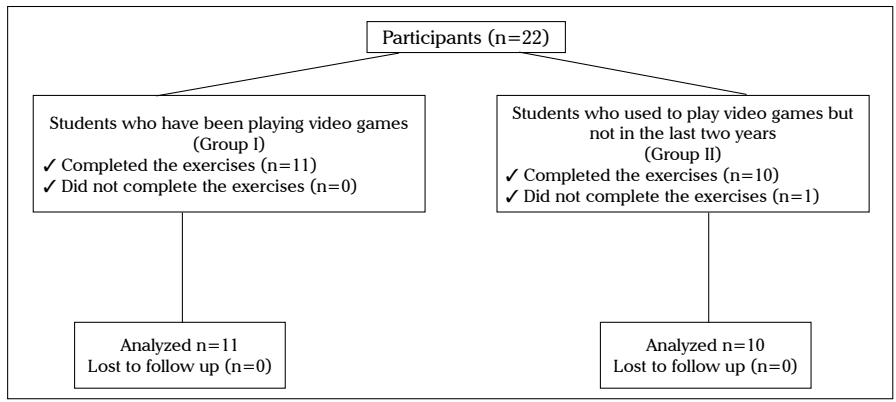

Figure 1. Participants were divided into Group I and Group II
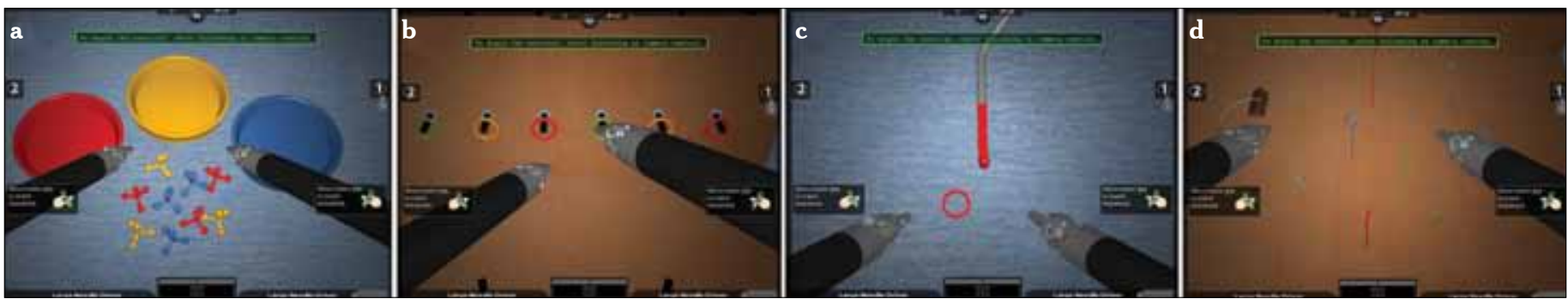

Figure 2. a-d. Sample screen shots of the 4 basic exercises: Pick and Place (a), Peg Board-1 (b), Ring and Rail (c), and Thread the Rings-1 (d) 
Table 1. Demographic and background characteristics

\begin{tabular}{|c|c|c|c|}
\hline & Group I & Group II & p value \\
\hline Median age (years) & $23(22-24)$ & $24(23-26)$ & 0.02 \\
\hline \multicolumn{4}{|l|}{$\operatorname{Sex}(n, \%)$} \\
\hline - Male & $10(90.9 \%)$ & $5(50 \%)$ & \multirow[t]{2}{*}{0.06} \\
\hline - Female & $1(9.1 \%)$ & $5(50 \%)$ & \\
\hline \multicolumn{4}{|c|}{ Starting period of playing video games (n, \%) } \\
\hline - Before primary school & - & - & - \\
\hline - During primary school & $9(81.8 \%)$ & $10(100 \%)$ & 0.47 \\
\hline $\begin{array}{l}\text { - During secondary } \\
\text { school or later }\end{array}$ & $2(18.2 \%)$ & - & - \\
\hline \multicolumn{4}{|c|}{ Video game history in the last 2 years } \\
\hline $\begin{array}{l}\text { - Average hours } \\
\text { per week (mean } \pm \text { SD) }\end{array}$ & $13.1 \pm 7.9$ & - & - \\
\hline $\begin{array}{l}\text { - Average days } \\
\text { per week (mean } \pm \mathrm{SD})\end{array}$ & $2.9 \pm 1.8$ & - & - \\
\hline
\end{tabular}

Table 2. Type of game console used and games played by the participants*

\begin{tabular}{|l|c|c|}
\hline & $\begin{array}{c}\text { Group I } \\
(\mathbf{n}=11)\end{array}$ & $\begin{array}{c}\text { Group II } \\
(\mathbf{n}=10)\end{array}$ \\
\hline Console Type & & \\
\hline Xbox & $6(54.5 \%)$ & $3(30 \%)$ \\
\hline Computer & $4(36.3 \%)$ & $5(50 \%)$ \\
\hline PlayStation & $1(9.1 \%)$ & $1(10 \%)$ \\
\hline Wii or Nintendo & - & $1(10 \%)$ \\
\hline Game Type & & \\
\hline First-person shooter game & $5(45.4 \%)$ & - \\
\hline Third-person shooter game & $1(9.1 \%)$ & - \\
\hline Racing & - & $2(20 \%)$ \\
\hline Sports games & $1(9.1 \%)$ & $2(20 \%)$ \\
\hline Strategy games & $4(36.3 \%)$ & $2(20 \%)$ \\
\hline Role-playing games & - & $4(40 \%)$ \\
\hline *The respondents may have used multiple console and game types \\
\hline
\end{tabular}

Table 3. Time to complete the exercises in seconds

\begin{tabular}{|l|c|c|c|}
\hline & $\begin{array}{c}\text { Group I } \\
\text { Median } \\
\mathbf{( 2 5 \% - 7 5 \% )}\end{array}$ & $\begin{array}{c}\text { Group II } \\
\text { Median } \\
\mathbf{( 2 5 \% - 7 5 \% )}\end{array}$ & $\begin{array}{c}\mathbf{p} \\
\text { value }\end{array}$ \\
\hline Pick and Place & $89(76-116)$ & $81(44-104)$ & 0.32 \\
\hline Peg Board-1 & $140(119-227)$ & $156(115-227)$ & 0.83 \\
\hline Ring and Rail & $104(66-118)$ & $86(58-140)$ & 0.75 \\
\hline Thread the Rings-1 & $291(229-568)$ & $264(211-325)$ & 0.39 \\
\hline
\end{tabular}

motion, instrument collision, use of excessive instrument force, instruments out of view, master workspace range, and drops, Group I had better results in 3 of 4 exercises, but none of them was statistically significant ( $p>0.05)$. Moreover, Group II's higher overall score in the remaining test was also not significant (p>0.05) (Table 4).
Table 4. Overall scores of each exercise among the participants

\begin{tabular}{|l|c|c|c|}
\hline & $\begin{array}{c}\text { Group I } \\
\text { Median } \\
\mathbf{( 2 5 \% - 7 5 \% )}\end{array}$ & $\begin{array}{c}\text { Group II } \\
\text { Median } \\
\mathbf{( 2 5 \% - 7 5 \% )}\end{array}$ & $\begin{array}{c}\mathbf{p} \\
\text { value }\end{array}$ \\
\hline Pick and Place & $80(76-88)$ & $86(78-92)$ & 0.45 \\
\hline Peg Board-1 & $61(58-73)$ & $52(46-70)$ & 0.19 \\
\hline Ring and Rail & $76(67-88)$ & $74(69-81)$ & 0.88 \\
\hline Thread the Rings-1 & $52(45-68)$ & $45(23-56)$ & 0.14 \\
\hline
\end{tabular}

\section{Discussion}

As MIS becomes more widespread, teaching robotic surgery will be essential to resident training programs, and video games can play a role in developing visuospatial skills. However, the present study revealed no statistically significant differences in the completion time or overall scores for the robotic simulation tests between students who used to play video games and those who still played video games.

The main strength of the study is that, to the best of our knowledge, it is the first to evaluate how past video game playing affects adoption of robotic surgical skills by comparing current players' abilities with past players' abilities, which may show whether previously acquired skills are adequate for performing robotic simulation. The study, however, has limitations. First, the main limitation is the power of the study. Although it was a prospective study, the sample size was small; thus, the results must be interpreted with caution. Nonetheless, this study was conducted as preliminary investigation and may provide a basis for future studies. The other limitation of the study is the lack of additional unmeasured variables, which may affect participants' motor skills. We cannot attribute the eye-brainhand coordination abilities only to video games. Moreover, some types of video games may have more beneficial effects than others. In this study, we did not ask the names of video games because they may number in hundreds for the medical students and concluding their individual effects would be impossible. Lastly, gender difference may present a bias in the study. Although we aimed to avoid gender bias, female students mainly comprised the group who had not played video games in the past 2 years. Our preliminary study is inadequate to comment on gender bias, and our results must be interpreted with caution. Nevertheless, in their study, Kolozsvari et al. (11) have supported the view that gender difference does not affect performance in early fundamental laparoscopic skill training. We previously evaluated the effect of gynecology residents' prior laparoscopic experience on the learning curve for robotic suturing techniques and found that residents with laparoscopic suturing experience may learn robotic surgery techniques more quickly than those with limited laparoscopic surgery experience (9). This transfer of laparoscopic surgery experience to robotic surgery sparked the idea of evaluating medical students' baseline abilities on a robotic simulator. Many studies in the literature suggest the possible positive effect of video games on learning laparoscopic skills $(6,8)$.

There are also studies evaluating the possible relationship of video games with robotic surgery skills. Shane et al evaluated 
whether surgical novices exposed to previous video game exercises would acquire new surgical skills faster than nonplayers and concluded that previous video game exercises shortened the time to achieve proficiency on 2 tasks on a validated surgical simulator (12).

In contrast to these studies, Harper et al collected information about the video game experiences of 242 preclinical medical students and chose 10 students with the highest and lowest video game exposure for closer examination to assess whether prior video game experience enhances the acquisition of robotic surgical skills. They concluded that medical students' prior video game exposure did not enhance robotic surgical performance (5).

Our study evaluated the visuospatial skills of experienced video game players who currently played video games versus those who had not played video games in the last 2 years and how those previously acquired visuospatial skills may relate to robotic surgery. Because baseline ability and eye-brain-hand coordination on the 3D screen may affect future surgeons' learning curves and skill levels, we need to perform studies to determine the optimal age and best methods for developing visuospatial skills.

Ethics Committee Approval: Ethics committee approval was received for this study from the ethics committee of the Institutional Review Board (IRB).

Informed Consent: Written informed consent was obtained from patients who participated in this study.

Peer-review: Externally peer-reviewed.

Author contributions: Concept - T.Ö., M.B.A., G.S.K.; Design - T.Ö., M.B.A., G.S.K.; Supervision - M.B.A., G.S.K.; Resource - T.Ö., M.B.A., T.A., G.S.K.; Materials - T.Ö., M.B.A., T.A., G.S.K.; Data Collection\&/or Processing - T.Ö., T.A.; Analysis\&/or Interpretation - T.Ö., T.A., G.S.K.; Literature Search - T.Ö., T.A.; Writing - T.Ö., M.B.A., G.S.K.; Critical Reviews - M.B.A., G.S.K.

Conflict of Interest: No conflict of interest was declared by the authors.

Financial Disclosure: The authors declared that this study has received no financial support.

\section{References}

1. Borahay MA, Haver MC, Eastham B, Patel PR, Kilic GS. Modular Comparison of Laparoscopic and Robotic Simulation Platforms in Residency Training: A Randomized Trial. J Minim Invasive Gynecol 2013; 20: 871-9. [CrossRef]

2. Lynch J, Aughwane P, Hammond TM. Video games and surgical ability: a literature review. J Surg Educ 2010; 67: 184-9. [CrossRef]

3. Griffith JL, Voloschin P, Gibb GD, Bailey JR. Differences in eye-hand motor coordination of video-game users and non-users. Percept Mot Skills 1983; 57: 155-8. [CrossRef]

4. Nielsen U, Dahl R, White RF, Grandjean P. Computer assisted neuropsychological testing of children. Ugeskr Laeger 1998; 160: 3557-61.

5. Harper JD, Kaiser S, Ebrahimi K, Lamberton GR, Hadley HR, Ruckle HC, Baldwin DD. Prior video game exposure does not enhance robotic surgical performance. J Endourol 2007; 21: 120710. [CrossRef]

6. Giannotti D, Patrizi G, Di Rocco G, Vestri AR, Semproni CP, Fiengo L, et al. Play to become a surgeon: impact of Nintendo Wii training on laparoscopic skills. PLoS One 2013; 8: e57372. [CrossRef]

7. Vaccaro CM, Crisp CC, Fellner AN, Jackson C, Kleeman SD, Pavelka J. Robotic virtual reality simulation plus standard robotic orientation versus standard robotic orientation alone: a randomized controlled trial. Female Pelvic Med Reconstr Surg 2013; 19: 266-70. [CrossRef]

8. Adams BJ, Margaron F, Kaplan BJ. Comparing video games and laparoscopic simulators in the development of laparoscopic skills in surgical residents. J Surg Educ 2012; 69: 714-7. [CrossRef]

9. Kilic GS, Walsh TM, Borahay M, Zeybek B, Wen M, Breitkopf D. Effect of residents' previous laparoscopic surgery experience on initial robotic suturing experience. ISRN Obstet Gynecol 2012; 2012: 569456. [CrossRef]

10. Liss MA, Abdelshehid C, Quach S, Lusch A, Graversen J, Landman $\mathrm{J}$, McDougall EM. Validation, correlation, and comparison of the da Vinci trainer and the daVinci surgical skills simulator using the Mimic software for urologic robotic surgical education. J Endourol 2012; 26: 1629-34. [CrossRef]

11. Kolozsvari NO, Andalib A, Kaneva P, Cao J, Vassiliou MC, Fried GM, Feldman LS. Sex is not everything: the role of gender in early performance of a fundamental laparoscopic skill. Surg Endosc 2011; 25: 1037-42. [CrossRef]

12. Shane MD, Pettitt BJ, Morgenthal CB, Smith CD. Should surgical novices trade their retractors for joysticks? Videogame experience decreases the time needed to acquire surgical skills. Surg Endosc 2008; 22: 1294-7. [CrossRef] 